\title{
Research on Education Quality Evaluation for Outstanding Engineers of Applied University
}

\author{
Ji-Hong PANG ${ }^{1, a^{*}}$, Xiao-Jing LIU ${ }^{2}$, Yu-Qing ZHOU ${ }^{1}$, Xiang-Lei ZHANG ${ }^{1}$ and \\ Yan REN ${ }^{1}$
}

${ }^{1}$ College of Mechanical and Electronic Engineering, Wenzhou University, Wenzhou 325035, Zhejiang, China

${ }^{2}$ School of Accounting, Wenzhou Business College, Wenzhou 325035, Zhejiang, China

${ }^{{ }^{\star}} E-$ mail: pangjihong@163.com

Keywords: Higher Education; Quality Evaluation; Outstanding Engineers; Applied University

\begin{abstract}
According to the requirements of engineers plans of China, it's becoming more and more important of education quality evaluation for outstanding engineers of applied university. Applied university as the base of training is of great strategic significance to improve the education quality for outstanding engineers. However, how to combine cultural traditions formed in education process is the key to current applied university need to solve this question. In this paper, an education quality evaluation system for outstanding engineers has both academic meaning and indicative value to the practice. Then, the weight of each criterion of education quality evaluation system is described by fuzzy analytic hierarchy process (FAHP). Finally, an example of an applied university is shown to highlight the feasibility and practicability of the approved methods.
\end{abstract}

\section{Introduction}

In recent years, a plan for outstanding engineers of applied university of China has been put into practice, so we should lay great emphasis on practical education and provide better scientists and businessmen. Along with education reforming go deep, engineer ability of applied university is measurement to improve education quality [1]. Those outstanding engineers have got full experience on manufacture and advanced productive technologies. University courses teaching affects the education quality for outstanding engineers of applied university directly [2]. These changes dramatically shorten the time to improve education quality by using an excellent teachers and students to participate in the outstanding engineers plan. The key point of outstanding engineers lies in good ethics and high levels of teachers [3]. Therefore, the social demand of employment guidance in higher colleges call the education quality evaluation.

In order to improve the capability of outstanding engineers, applied universities must implement quality cultivation and put practice in the first place. Firstly, the education quality evaluation standards for outstanding engineer of applied university is the guarantee for the practical teaching. The education quality evaluation for outstanding engineers is directly related to the qualities of student's cultivation [4]. Then, the reform of evaluation systems ought to lead the way for higher education, and students' practical capacity will be enhanced in this way. The education quality for outstanding engineers demands strengthening courses construction and promoting the students' abilities to solve problems [5]. It is also necessary to build good environmental construction for higher institutions of education and strengthen the education of personal knowledge and ability.

According to the above analysis, some measures to accelerate educational information construction were raised to improve the education quality of outstanding engineers. In order to evaluate education quality for outstanding engineers, this paper is organized as follows. Next section introduces the education quality evaluation system for outstanding engineers based on FAHP. The proposed method by using the fuzzy number and linguistic variable is illustrated with an example. Finally, some conclusions are drawn out and few weaknesses are pointed out in this paper. 


\section{Education Quality Evaluation System for Outstanding Engineers}

A completed education quality evaluation system of outstanding engineers should be carried out for the advancement of innovation experimental program of applied university. In order to meet the urgent needs of higher education industry, improving the education quality for outstanding engineers is a task which brooks no delay [6]. Both the education administration and evaluation should be normalized by building an evaluation system with country, locality, university, student and society together. A lot of people think that it's better to advance the mordent progress of educational means and educational methods so that they can be sure of getting evaluation quality [7]. It also deals with how to evaluate education quality for outstanding engineers and how to build a scientific evaluation system in university education.

On the other hand, an excellent education quality evaluation system is the key and guarantee for quality of outstanding engineers. As the most fundamental element, the validity of evaluation index system is directly related to a college education for outstanding engineers [8]. In most cases it is a key index to measure education quality evaluation by the application of scientific method and knowledge. The quality of specialized course of applied university will influence education level of outstanding engineers and their future directly. At the same time, through research the training goal to show education quality guarantee system of outstanding engineers.

The quality of education for outstanding engineers can be effectively improved by using modern educating evaluation technology. Focusing on the application of FAHP, this paper gives a detailed description and includes an explanation of the evaluation model. The indexes system of comprehensive benefit of education quality was built and the FAHP was employed to analyze this evaluation system. The scientific and reasonable evaluation index system to improve education quality for outstanding engineers was given in this paper, which was shown in Fig. 1.

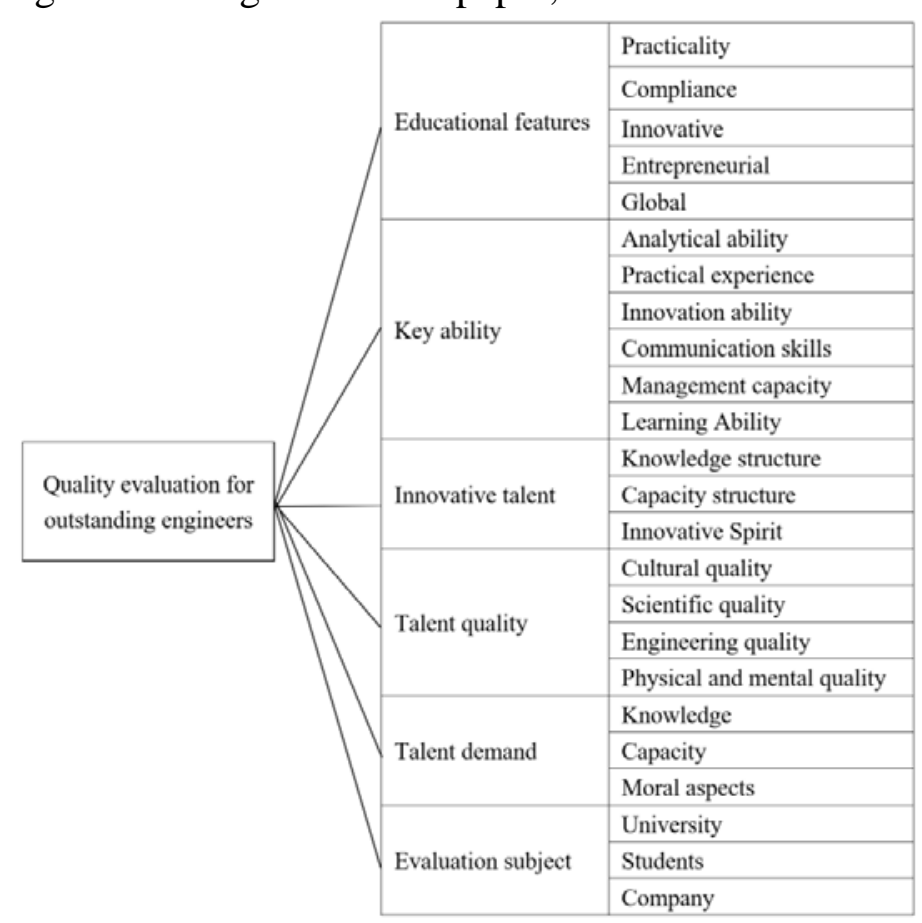

Figure. 1. Education quality evaluation index system for outstanding engineers of applied university 
The application of fuzzy mathematics theory and analytic hierarchy for education quality evaluation for outstanding engineers of applied university was given in this paper. The education quality for outstanding engineers was evaluated and result was available based on fuzzy method and analytic hierarchy process. This paper makes education quality evaluation for outstanding engineers in economy and technological innovation, puts forward a scientific and precise evaluation method based on the hierarchical analysis.

In this paper, an education quality evaluation system was developed by using knowledge engineering and FAHP. According to the quality characteristics of outstanding engineers in school and beyond, the choice method of search way in this study was optimized based on FAHP [9]. FAHP which fits people's judging consciousness was applied to solve the education quality evaluation for outstanding engineers [10]. FAHP model has high efficiency and practice with fully consider the effect of expert group's judgments based on linguistic judgment matrices [11]. An education quality evaluation strategy based on FAHP was proposed as a mean to avoid evaluation index change.

In order to solve the question of consistency test of FAHP, the random consistency indicators of section numbers judging matrix was approved in this paper. Calculating procedures and formulas of FAHP for education quality evaluation of outstanding engineers of applied university are given in this paper in the following.

(1) Grading and fuzzy ordering

The Grading and fuzzy ordering was acquired based on sequencing theory of fuzzy numbers. This paper has put forward a new fuzzy evaluation scale of rapid ambiguity resolution for education quality evaluation indexes.

(2) Building fuzzy priority relation array

The fuzzy priority relation array of fuzzy consistent complementary judgment matrix with priority is pointed out by using the consistent transformation formula. And on above basis, the fuzzy priority relation array can be built quickly.

$$
\begin{aligned}
& A=\left[\begin{array}{cccc}
a_{11} & a_{21} & \mathrm{~L} & a_{n 1} \\
a_{12} & a_{22} & \mathrm{~L} & a_{\mathrm{n} 2} \\
\mathrm{M} & \mathrm{M} & \mathrm{O} & \mathrm{M} \\
a_{1 m} & a_{2 m} & \mathrm{~L} & a_{n m}
\end{array}\right] \\
& a_{i n}=0.5 . \quad i=1,2, \mathrm{~K}, m \\
& a_{i n}+a_{n i}=1 . \quad i, n=1,2, \mathrm{~K}, m
\end{aligned}
$$

(3) Computing priority values

The priority values of evaluation paths can be computed based on the fuzzy priority relation array. Of course, taking full advantage of the priority values available will give the best chance of meeting the overall.

$$
B=\left[\begin{array}{c}
B_{1} \\
B_{2} \\
\mathrm{M} \\
B_{i}
\end{array}\right]=\left[\begin{array}{cccc}
b_{11} & b_{12} & \mathrm{~L} & b_{1 n} \\
b_{12} & b_{22} & \mathrm{~L} & b_{2 n} \\
\mathrm{M} & \mathrm{M} & \mathrm{O} & \mathrm{M} \\
b_{1 m} & b_{i 2} & \mathrm{~L} & b_{\text {in }}
\end{array}\right]
$$

(4) Sorting single hierarchy

Based on FAHP, the indexes set attribute value of each hierarchy from bottom to top can be calculated and analyzed the calculations by our own approach. 


$$
\begin{aligned}
S_{i}^{k}= & 1 / n-1 / 2 \alpha^{+} \sum_{i=1}^{n} a_{n m} / n \alpha \cdot \quad(i=1,2, \mathrm{~K}, n) \\
& \alpha \geq(n-1) / 2
\end{aligned}
$$

(5) Obtaining total sequencing

The sequencing method can reduce the total delay of the system as much as possible by using the weights for main sequencing factors. Then, the total sequencing of each level is given in the following.

$$
W_{i}=\sum_{k=1}^{n} w_{k} \cdot S_{i}^{k} \quad(i=1,2, \mathrm{~K}, n)
$$

Evaluation on education quality is an important method to intensify the applied university teaching management and improve outstanding engineers’ performance based on FAHP.

\section{A Case Study}

Education quality for outstanding engineers is the key work to the applied university. It's related to the engineering students' ability of innovation and practice and the positive development of society. Teachers, students, and the curriculum system are the three basic factors of education quality for outstanding engineers of applied university. The guarantee and improvement of education quality for outstanding engineers not only rely on teaching conditions, such as supply of teachers, efficient management systems and processes, buildings, but also on a scientific justice university education quality system. There are various elements that determine the education quality for outstanding engineers of a college or university. Among which, accurate evaluation policy is of great importance in insuring engineer ability learning and education quality.

How to evaluate the education quality for outstanding engineers of applied university has become the focus attention of the public. In the next section we'll expand on these points by using a case study involving outstanding engineers of applied university in China. An education quality evaluation index

\begin{tabular}{|c|c|c|}
\hline \multirow{12}{*}{$\begin{array}{l}\text { Education quality } \\
\text { evaluation }\end{array}$} & \multirow{5}{*}{$\begin{array}{l}\text { Knowledge } \\
\text { structure }\end{array}$} & $\begin{array}{l}\mathrm{Q}_{1} \text { : Knowledge of basic } \\
\text { disciplines }\end{array}$ \\
\hline & & $\mathrm{Q}_{2}$ : Technical knowledge \\
\hline & & $\begin{array}{l}\mathrm{Q}_{3}: \text { Knowledge of related } \\
\text { disciplines }\end{array}$ \\
\hline & & $\mathrm{Q}_{4}$ : Knowledge of social sciences \\
\hline & & $\mathrm{Q}_{5}$ : Instrumental knowledge \\
\hline & \multirow{4}{*}{$\begin{array}{l}\text { Capacity } \\
\text { structure }\end{array}$} & $\mathrm{Q}_{6}$ : Practical ability \\
\hline & & $\mathrm{Q}_{7}$ : Innovation ability \\
\hline & & $\mathrm{Q}_{8}$ : Management capacity \\
\hline & & $\mathrm{Q}_{9}$ : Social adaptability \\
\hline & \multirow{3}{*}{ Moral character } & $\mathrm{Q}_{10}$ : Personal accomplishment \\
\hline & & $\mathrm{Q}_{11}$ : Morality \\
\hline & & $\mathrm{Q}_{12}$ : Ethics \\
\hline
\end{tabular}
system for outstanding engineer is shown in Table 1.

Table 1. Education quality evaluation index system for outstanding engineer 
Based on FAHP, the deriving weights from the interval complementary judgment matrix is developed by specialist team members, which is shown in the following:

\begin{tabular}{|l|l|l|l|l|l|l|r|r|}
\hline 1.000 & 1.000 & 1.000 & 1.500 & 1.000 & 1.250 & 1.500 & 3.000 & 2.000 \\
\hline 1.000 & 1.000 & 1.000 & 1.500 & 2.000 & 1.500 & 1.750 & 3.000 & 2.000 \\
\hline 1.000 & 1.000 & 1.000 & 1.500 & 0.500 & 0.500 & 2.500 & 3.000 & 2.000 \\
\hline 0.800 & 1.000 & 0.667 & 1.000 & 1.000 & 1.000 & 0.500 & 0.250 & 2.250 \\
\hline 0.667 & 0.500 & 0.667 & 1.000 & 1.000 & 1.000 & 0.250 & 0.250 & 3.500 \\
\hline 2.000 & 2.000 & 0.667 & 1.000 & 1.000 & 1.000 & 1.250 & 0.250 & 1.500 \\
\hline 0.500 & 0.333 & 0.667 & 0.444 & 4.000 & 2.000 & 1.000 & 1.000 & 1.000 \\
\hline 0.500 & 0.333 & 0.571 & 0.286 & 4.000 & 4.000 & 1.000 & 1.000 & 1.000 \\
\hline 0.500 & 0.333 & 0.400 & 0.667 & 4.000 & 0.800 & 1.000 & 1.000 & 1.000 \\
\hline
\end{tabular}

Then, the fuzzy priority relation array of fuzzy consistent complementary judgment matrix can be get by calculating with FAHP, as shown below.

\begin{tabular}{|r|r|r|r|r|r|r|r|r|}
\hline 1.00 & 1.00 & 1.00 & 1.50 & 1.16 & 1.08 & 1.91 & 3.00 & 2.00 \\
0 & 0 & 0 & 0 & 7 & 3 & 7 & 0 & 0 \\
\hline 1.15 & 1.16 & 0.66 & 1.00 & 1.00 & 1.00 & 0.66 & 0.25 & 2.41 \\
6 & 7 & 7 & 0 & 0 & 0 & 7 & 0 & 7 \\
\hline 0.50 & 0.33 & 0.54 & 0.46 & 4.00 & 2.26 & 1.00 & 1.00 & 1.00 \\
0 & 3 & 6 & 6 & 0 & 7 & 0 & 0 & 0 \\
\hline
\end{tabular}

At the same time, it shows the normalization arithmetic and concrete process to get the global mode. Complying with the FAHP model, fuzzy numbers between evaluation index and identity evaluation parameters were established, the weight array is shown in the following.

$$
W=(0.431,0.117,0.451)
$$

So similarly, the quality evaluation indicators can be get in Table 2 .

Table 2. Weight of quality evaluation indicators

\begin{tabular}{|c|c|c|}
\hline \multicolumn{3}{|c|}{ Quality evaluation indicators } \\
\hline First level index & Second level index & Third level index \\
\hline \multirow{4}{*}{$\begin{array}{c}\text { Knowledge structure } \\
(0.232)\end{array}$} & $\mathrm{Q}_{1}: 0.134$ & $\mathrm{~W}_{1}: 0.0311$ \\
\cline { 2 - 3 } & $\mathrm{Q}_{2}: 0.156$ & $\mathrm{~W}_{2}: 0.0362$ \\
\cline { 2 - 3 } & $\mathrm{Q}_{3}: 0.271$ & $\mathrm{~W}_{3}: 0.0629$ \\
\cline { 2 - 3 } & $\mathrm{Q}_{4}: 0.223$ & $\mathrm{~W}_{4}: 0.0517$ \\
\cline { 2 - 3 } & $\mathrm{Q}_{5}: 0.216$ & $\mathrm{~W}_{5}: 0.0501$ \\
\hline \multirow{4}{*}{$\begin{array}{c}\text { Capacity structure } \\
(0.354)\end{array}$} & $\mathrm{Q}_{6}: 0.215$ & $\mathrm{~W}_{6}: 0.0761$ \\
\cline { 2 - 3 } & $\mathrm{Q}_{7}: 0.114$ & $\mathrm{~W}_{7}: 0.0404$ \\
\cline { 2 - 3 } & $\mathrm{Q}_{8}: 0.352$ & $\mathrm{~W}_{8}: 0.1246$ \\
\hline \multirow{3}{*}{$\begin{array}{c}\text { Moral character } \\
(0.414)\end{array}$} & $\mathrm{Q}_{9}: 0.319$ & $\mathrm{~W}_{9}: 0.1129$ \\
\cline { 2 - 3 } & $\mathrm{Q}_{10}: 0.431$ & $\mathrm{~W}_{10}: 0.1784$ \\
\cline { 2 - 3 } & $\mathrm{Q}_{11}: 0.117$ & $\mathrm{~W}_{11}: 0.0484$ \\
\cline { 2 - 3 } & $\mathrm{Q}_{12}: 0.451$ & $\mathrm{~W}_{12}: 0.1867$ \\
\hline
\end{tabular}

Therefore, evaluate the results and design guidelines providing managers with dos and don'ts. To develop education quality evaluation activities effectively plays an important role in improving 
practical skills and ability to apply theory to practice. At last the paper discusses how to strengthen education management, accordingly improving the quality of outstanding engineers.

\section{Conclusion}

Education quality evaluation is an important work concerning with teaching quality, science research and future development of outstanding engineers. Education evaluation is one of the main means to guarantee and promote the quality for outstanding engineers of applied university. However, how to improve the quality of the practice on outstanding engineers with high ability are the tasks which many applied universities are exploited. This paper has an attempt to discuss the concept of education quality, evaluation system and unique connotations of applied university.

A new model was proposed in this study by analyzing the significance and procedure of outstanding engineers with a comprehensive plan and assessment. This paper explores on the education quality evaluation system of outstanding engineers under the multimedia teaching mode of applied university. The methods of analytic hierarchy process, fuzzy evaluation and composite analysis were introduced that affected many evaluation technologies. The practice has showed that the education quality is also improved obviously. It proves that the education quality of outstanding engineers can be enhanced through many measures and fuzzy math methods.

\section{Acknowledgement}

This research was supported by the key project of teaching reform of Wenzhou University (No.15jg07), engineering practice education center of Wenzhou University \& Zhejiang Linuo fluid control Technology Co, higher education classroom teaching reform research project of Zhejiang (No.kg2015601) and project of teaching reform of Wenzhou University (No.17jg32, No. 16jg51).

\section{References}

[1] Teeroovengadum V, Kamalanabhan T J, Seebaluck A K. Measuring service quality in higher education[J]. Quality Assurance in Education, 2016, 24(2):244-258.

[2] Akareem H S, Hossain S S. Determinants of education quality: what makes students' perception different?[J]. Open Review of Educational Research, 2016, 3(1):52-67.

[3] Thangeda A, Baratiseng B, Mompati T. Education for Sustainability: Quality Education Is a Necessity in Modern Day. How Far Do the Educational Institutions Facilitate Quality Education?[J]. Journal of Education and Practice, 2016, 7(2): 9-17.

[4] Pereira D, Flores M A, Niklasson L. Assessment revisited: a review of research in Assessment and Evaluation in Higher Education[J]. Assessment \& Evaluation in Higher Education, 2015, 41(7):1-25.

[5] Chou B K P. The Paradox of Educational Quality and Education Policy in Hong Kong and Macau[J]. Chinese Education \& Society, 2012, 45(2):96-110.

[6] David Pyvis. The need for context-sensitive measures of educational quality in transnational higher education[J]. Teaching in Higher Education, 2011, 16(6):733-744.

[7] Scheerens J. Perspectives on education quality, education indicators and benchmarking[J]. European educational research journal, 2004, 3(1): 115-138.

[8] Bergsmann E, Schultes M T, Winter P, et al. Evaluation of competence-based teaching in higher education: From theory to practice[J]. Evaluation and program planning, 2015, 52: 1-9.

[9] Kubler S, Robert J, Derigent W, et al. A state-of the-art survey \& testbed of fuzzy AHP (FAHP) applications[J]. Expert Systems with Applications, 2016, 65:398-422. 
[10] Geng Z, Wang Z, Peng C, et al. A New Fuzzy Process Capability Estimation Method Based on Kernel Function and FAHP[J]. IEEE Transactions on Engineering Management, 2016, 63(2):177-188.

[11] Zhang H, Aicha, Yacine, et al. A PLM components monitoring framework for SMEs based on a PLM maturity model and FAHP methodology[J]. Journal of Modern Project Management, 2016, 2(1):109-119. 